\title{
Critical Thinking, Reflection, and Action Research as Cornerstones of NIDCAP Implementation
}

Hasanpour M, Kakavand A

School of Nursing and Midwifery, Tehran University of Medical Sciences, Tehran, Iran.

\section{Aims}

To describe the foundations necessary to develop a Newborn Intensive Care Unit (NICU) training and staff development plan that will effectively support the changes in environment and care required for successful implementation of developmental care in the NIDCAP model. ${ }^{1}$ To determine the research method which is most appropriate and the abilities that professionals need to implement NIDCAP in the NICU. The aim of this presentation is to focus on Action Research, Reflection, and Critical Thinking as Cornerstones of NIDCAP Implementation.

\section{Methods}

Review of literature and results of author's previous grounded theory qualitative research on critical thinking process. $^{2}$

\section{Results}

NIDCAP is an evidence based model that focuses on system change. ${ }^{1}$ A change would require the acceptance of new ideas or a new structure. Action research is methodologically flexible to the point that it encourages methodological triangulation/ pluralism approaches. The process seeks to have full engagement by researchers and participants. The process is truly collaborative. An action or change is the focal point of the process. The decision to implement the action or change is in the hands of the stakeholders. The conclusion and subsequent action must reflect the collective thinking of the group. Early work is attributed to Lewin, a social psychologist, who is cited frequently as the first person who coined the term action research. Simplistically, Lewin said that for a change to occur, individuals would need to unfreeze-give up their ideas about something or give up the dominant structure. ${ }^{3}$ They would then need to change. An important characteristic of action research is the empowerment of others. Change may come in the form of individual or group empowerment, greater community capacity to solve shared problems, or transformed organizational structures.

An important part of the change or action phase of the research process is reflection. Data recorded during reflection are important contributions to the theory that emerges from the action research study. ${ }^{4}$ Reflection is a very important skill for professionals within the NIDCAP model. It is a skill used in two contexts - during events and after them. It involves the use of decision making and evaluation. Reflection is a process whereby experience is examined in ways that give meaning to interaction; interaction and engagement are very important components of the NIDCAP Model. Reflection is most closely associated with human interactions and especially clinical events too. Some reasons why reflection is important in nursing and in helping to implement NIDCAP in the NICU are: Correcting practice, Understanding self; others; Professions, and challenging assumptions. There are two types of reflection: in action and on action in three levels: Superficial, Medium, and Deep. ${ }^{5}$ One of the most popular models of reflection is Gibbs' model. ${ }^{6}$ In the NIDCAP model, developmental specialists need this ability for writing journal pages on his/her observation of premature and caregiver behavior and

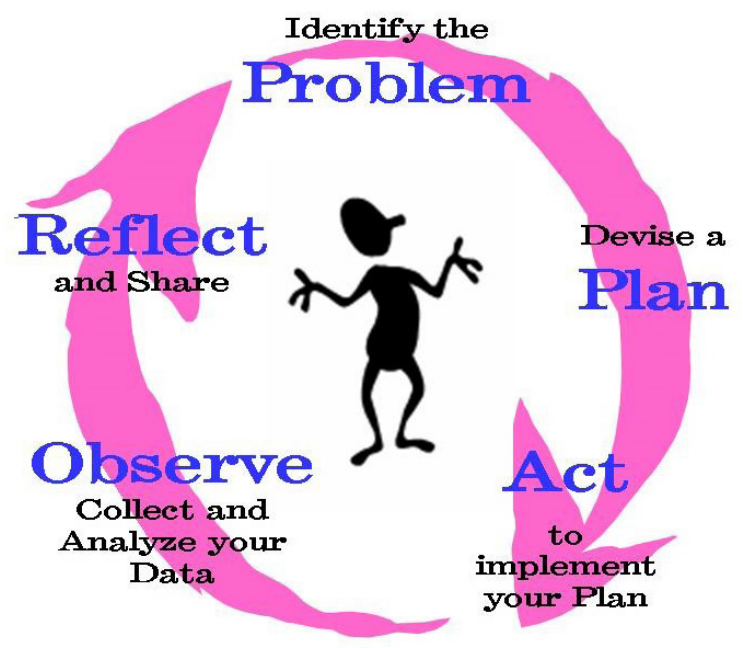

Elements of Action Research Method

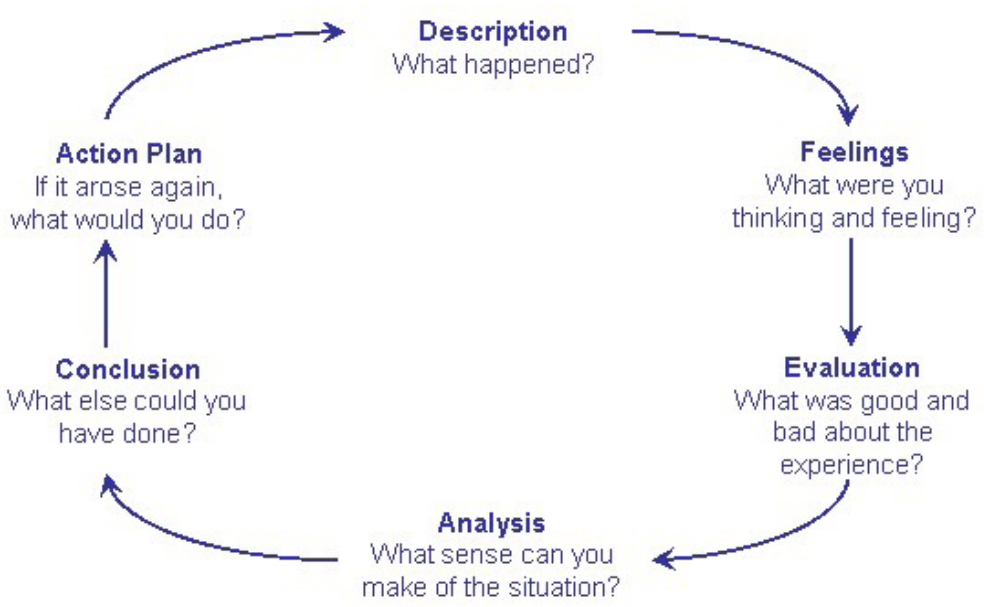

Gibbs, G. (1988). Learning by Doing: A Guide to Teaching and Learning Methods 
to foster good relationships with other staff, as well as the infant's family. Reflection is a subset of critical thinking and one that is used in close association with experience.

Critical Thinking is another cornerstone of NIDCAP implementation. According to the results of qualitative grounded theory research in Iran, critical thinking is the art of thinking and the mental challenge of how you are thinking. It is an essential concept, a fundamental ability and necessary means for human evolution and the overcoming of the problems of life in society, workplace and education. It is also an essential ability to achieve self-efficacy, autonomy and professional development. ${ }^{7}$ Decision making, leadership and ethical practice are all founded upon an ability to think critically. We use critical thought to select resources, to utilize knowledge and to evaluate evidence. Traditionally, our thinking has been designed for routine, habit, automation and fixed procedure. But the problems we now face, and will increasingly face, require a radically different form of thinking, thinking that is more complex, more adaptable, and more sensitive to divergent points of view. ${ }^{8}$ The ability to think critically is considered an essential educational outcome for today's college graduates ${ }^{9}$ and necessary to NIDCAP implementation.

\section{Conclusion}

The goal of the NIDCAP Model is to bring about a shift from protocol-based to strategic process thinking and from task-oriented to relationship-based care. To achieve these goals and implement NIDCAP, there is a need for professionals to be familiar with three cornerstones including: Action Research, Reflections and Critical Thinking. It is recommended that medical and nursing schools focus on special training programs to improve these abilities in students, since creating behavior is easier than changing behavior. Also, enhance these abilities in NICU nurses and medical staff through continuing education workshops before and during NIDCAP Implementation.

References:

1. Als, H. Program Guide Newborn Individualized Developmental Care and Assessment Program (NIDCAP). ${ }^{\circ}$ NIDCAP Federation International, 2015, rev 31 May 2018.

2. Hasanpour M, Oskouie F, Salsali M.(2007) The process of critical thinking in Iranian nursing education: A Qualitative Research. http://www.criticalthinking.org/pages/29th-conferenceconcurrent-sessions/868

3. Speziale \& Streubert, H. (2011). Qualitative research in nursing: advancing the humanistic imperative.

4. Brown, L. D., \& Tandon, R. (2008). Action research, partnerships and social impacts: The institutional collaboration of PRIA and IDR. In P. Reason, \& H. Bradbury (Eds.), The Sage handbook of action research: Participative inquiry and practice (2nd ed., pp. 227-234). Los Angeles: Sage

5. Price B. and Harrington A. (2010).Transforming Nursing practice: Critical Thinking and Writing for Nursing Students. Learning Matters Ltd.co.uk.

6. Dye, V. (2011) 'Reflection, Reflection, Reflection. I'm thinking all the time, why do I need a theory or model of reflection?', in McGregor, D. and Cartwright, L. (ed.) Developing Reflective Practice: A guide for beginning teachers. Maidenhead: McGraw-Hill Education (pp. 217-234).

7. Elder L. and Paul W R. (2002).Critical thinking. New York, Pearson Education, Inc.

8. Emerson J R. (2007) Nursing Education in Clinical Setting. Mosby, Elsevier Co, United State of America

9. Current project underway at Tehran University of Medical Sciences (TUMS) - developing critical thinking of NICN Students based on the practive of reflection.

8 2019 - Developmental Observer 